\title{
Prevalence and Risk Factors of Respiratory Viral Infections in Exacerbations of Chronic Obstructive Pulmonary Disease
}

\author{
Hyun Jung Kwak, ${ }^{1, *}$ Dong Won Park, ${ }^{1, *}$ Jee Eun Kim, ${ }^{1}$ Min Kyung Park, ${ }^{1}$ \\ Gun Woo Koo, ${ }^{1}$ Tai Sun Park, ${ }^{1}$ Ji-Yong Moon, ${ }^{1}$ Tae Hyung Kim, ${ }^{1}$ Jang Won Sohn, ${ }^{1}$ \\ Ho Joo Yoon, ${ }^{1}$ Dong Ho Shin ${ }^{1}$ and Sang-Heon Kim ${ }^{1}$ \\ ${ }^{1}$ Department of Internal Medicine, Hanyang University College of Medicine, Seoul, Korea
}

\begin{abstract}
Exacerbations of chronic obstructive pulmonary disease (COPD) lead to high morbidity and mortality. Respiratory virus infection is considered as one of the important causes of COPD exacerbations. The aim of this study was to assess the prevalence of respiratory virus infection in COPD exacerbations and to find the factors associated with susceptibility to viral infections. Furthermore, we tried to examine if COPD exacerbations caused by viral infections have more severe clinical outcomes in comparison with those with non-viral causes. We enrolled the patients with acute exacerbations of COPD who were hospitalized in a university hospital, over a 2-year period. Nasopharyngeal swabs were taken and viruses were identified by multiplex polymerase chain reaction. A total of 278 episodes of COPD exacerbations were recorded in 213 patients with COPD (number of females $=73$ ). Among the COPD exacerbations, viral infection was detected in 78 episodes (28.1\%) from 67 subjects. The most common virus was rhinovirus $(38.8 \%)$, followed by respiratory syncytial virus, coronavirus, influenza A, parainfluenza, adenovirus and metapneumovirus. In multivariate regression analysis adjusting for sex, age, BMI, lung function and history of exacerbations, female subjects were found to be significantly associated with viral infections in COPD exacerbations (Odds ratio $2.58,95 \% \mathrm{Cl} 1.25-5.31, P=0.010$ ). The severity of COPD exacerbations were not different between positive and negative viral detections. In conclusion, the prevalence of viral infection was $28.1 \%$ in the hospitalized patients with COPD exacerbations. Moreover, female subjects are at significantly higher risk for viral infections in COPD exacerbations.
\end{abstract}

Keywords: chronic obstructive pulmonary disease; exacerbation; infection; multiplex polymerase chain reaction; respiratory virus

Tohoku J. Exp. Med., 2016 October, 240 (2), 131-139. (C) 2016 Tohoku University Medical Press

\section{Introduction}

Exacerbations are one of key characteristics of chronic obstructive pulmonary disease (COPD), often leading to serious morbidity and mortality in affected subjects (Wedzicha and Seemungal 2007). Furthermore, COPD exacerbations require healthcare utilization, including visits to emergency rooms and hospital admission, thus the medical cost is substantial (Foster et al. 2006). More rapid decline and lung function and clinical outcomes are associated with the frequent exacerbations of COPD (Donaldson et al. 2002). Thus, understanding and prevention of exacerbation are very important in the management of COPD.

Traditionally, bacterial infection has been regarded as the most important cause of COPD exacerbations. However, viral infections also contribute to the development of exacerbations of COPD (Matsumoto and Inoue
2014). While the frequency of detection of viruses by serology or cell culture has been reported to be low as 15 to $20 \%$ (Beasley et al. 2012), introduction of polymerase chain reaction (PCR) methods raised the detection rate of virus up to $57 \%$ of cases in previous studies in patients with COPD exacerbations (Wu et al. 2014). Rhinovirus, respiratory syncytial virus (RSV) and influenza have been identified as major causative pathogens leading to exacerbations of COPD in the previous studies (Zwaans et al. 2014). It seems that there are geographic variations not only in overall viral prevalence among COPD exacerbations and but in the contributions of each virus pathogen (Mohan et al. 2010). While rhinovirus was the most common viral pathogen in the western countries, influenza was most commonly detected in Hong Kong (Ko et al. 2007a). However, it is not clear whether influenza is the leading viral pathogen associated with COPD exacerbations in the other Asian

Received July 27, 2016; revised and accepted September 16, $2016 . \quad$ Published online October 5, 2016; doi: 10.1620/tjem.240.131.

*These two authors equally contributed to this work.

Correspondence: Sang-Heon Kim, M.D., Ph.D., Division of Pulmonary Medicine and Allergy, Department of Internal Medicine,

Hanyang University College of Medicine, 222 Wangsimni-ro, Seongdong-gu, Seoul 04763, Korea.

e-mail: sangheonkim@ hanyang.ac.kr 
countries.

A previous study in the UK showed that frequent exacerbations are linked with increased risk of acquiring common cold in the patients with COPD (Hurst et al. 2005). In addition, low lung function and more severe airway disease were associated with more frequent viral infections (McManus et al. 2008). However, little is known about the predisposing factors and susceptibility to virus infections leading to exacerbations in the patients with COPD. In addition, it is not clear whether COPD exacerbations caused by virus infection have worse clinical outcomes than the other causes. Although a few studies suggested that respiratory viral infections are associated with more severe symptoms and delayed recovery of COPD exacerbations (Seemungal et al. 2001; Rohde et al. 2003), there are conflicting data on the clinical course and outcomes of viral infection induced COPD exacerbations (Boixeda et al. 2012).

This study was aimed to determine the prevalence of respiratory viral infections and to find the factors associated with susceptibility to viral infections. For the analysis of respiratory viruses, we used nasopharyngeal swabs and multiplex PCR, which can detect various viruses with high sensitivity and accuracy at the same time (Kim et al. 2009). We also compared the severity of COPD exacerbations caused by viral infection in comparison with non-viral infections.

\section{Methods}

Subjects

We recruited the study subjects with exacerbations of COPD, who had been hospitalization for the management of exacerbations in Hanyang University Hospital, Seoul, Korea, over a 2-year period between January $1^{\text {st }} 2010$ and December $31^{\text {th }} 2011$. The presence of COPD was confirmed based on clinical manifestations and postbronchodilator spirometry (the ratio of forced expiratory volume in $1 \mathrm{sec}-$ ond $\left(\mathrm{FEV}_{1}\right)$ over forced vital capacity (FVC) less than $70 \%$ ). We defined an exacerbation of COPD as an acute change in more than two respiratory symptoms (dyspnea, cough, and/or sputum) beyond normal day-to-day variation requiring a change in medication for COPD as indicated by the Global Initiative for Obstructive Lung Disease (GOLD) (Vestbo et al. 2013). Among the patients with an exacerbation of COPD, we included the patients who had been hospitalization based on the evaluation of the severity by the clinicians. Exclusion criteria were the other chronic respiratory diseases other than COPD, such as asthma and interstitial lung diseases, lung cancer, refusal of the enrollment and admissions due to non-respiratory causes. The study approved by the Institutional Review Board of Hanyang University Hospital and all the study subjects signed an informed consent form.

\section{Demographic and clinical information and microbiological sampling}

Within 24 hours of admission, nasopharyngeal swabs were taken from all participants for the detection of respiratory virus. Sterile dacron-tipped swabs were inserted into the nostrils to a depth of 2-3 cm (just past the point of resistance) and the tips rolled on the mucosa. The sample was stored at $-70^{\circ} \mathrm{C}$ for the further experiments.
The attending physicians were blind to the results of virus detection and treatment of exacerbations was made according to the international guideline of COPD irrespective of the virus positivity. The demographic and clinical characteristics at baseline before exacerbations were assessed and recorded: age, gender, body mass index (BMI), smoking history, postbronchodilator spirometry within 12 months of exacerbation, medications for COPD and history of exacerbations of COPD in the lifetime and in the previous 12 months. Clinical findings and laboratory tests at the time of admission were also recorded. In addition, we assessed the hospital courses of the study subjects including hospital days, ICU care and death in the study subjects.

\section{Multiplex PCR for detection of respiratory viruses}

To detect respiratory virus from the nasopharyngeal swab samples, multiplex PCR was performed targeting seven respiratory viral pathogens: RSV A and B, influenza A and B, parainfluenza, metapneumovirus, coronavirus and rhinovirus. Viral DNA/RNA was extracted from $300 \mu \mathrm{l}$ of each respiratory specimen using a Viral Gene-Spin ${ }^{\mathrm{TM}}$ Kit (Seegene Inc., Seoul, Korea) to the manufacturer's instructions, as described previously elsewhere (Sung et al. 2008). cDNA synthesis was performed using a RevertAid ${ }^{\mathrm{TM}}$ First Strand cDNA Synthesis Kit (Fermentas, Ontario, Canada) with cloned murine leukemia virus reverse transcriptase. Multiplex PCR was then performed with reactions containing $3 \mu \mathrm{l}$ of synthesized first-strand cDNA, $4 \mu \mathrm{l}$ of multiplex primer sets and $10 \mu \mathrm{l}$ of master mix (including hot start TaqDNA polymerase and dNTPs). Prior to the addition of the cDNA, $3 \mu \mathrm{l}$ of 8-methoxypsoralen (8-MOP) was added to each reaction followed by UV irradiation for $20 \mathrm{~min}$ to prevent amplification of contaminating DNA. The reaction mixtures were stored at $-20^{\circ} \mathrm{C}$ until use. An internal control comprising a solution of DNA extracted from plants (Seegene Inc., Seoul, Korea) was used for validation of the PCR. A mixture of 12 viral clones was used for a positive control and sterile deionized water was used as a negative control. After preheating at $95^{\circ} \mathrm{C}$ for 15 min, 40 amplification cycles were carried out in a thermal cycler (GeneAmp PCR system9700, Foster City, CA) with the following steps: $94^{\circ} \mathrm{C}$ for $30 \mathrm{sec}, 60^{\circ} \mathrm{C}$ for $1.5 \mathrm{~min}$, and $72^{\circ} \mathrm{C}$ for $1.5 \mathrm{~min}$. Amplification was completed with a final extension step at $72^{\circ} \mathrm{C}$ for $10 \mathrm{~min}$. PCR products were visualized by electrophoresis on a $2 \%$ agarose gel containing ethidium bromide. Specimen processing, DNA/RNA extraction, PCR amplification, and PCR product analyses were conducted in different rooms. Special care was taken to avoid contamination with RNAase and cross-contamination between reactions.

\section{Statistical analysis}

Data were analyzed using SPSS (version 19.0, Chicago, IL). Demographic and clinical characteristics were compared between the patients with viral infection and those with non-viral causes. Normally distributed data were compared by t-test; otherwise, the differences were assessed by the Mann-Whitney U-test. Normally distributed data were presented as the mean \pm standard deviation (SD). Symptoms and other clinical characteristics were binary coded and for discrete variables frequencies and percentages were reported and groups compared using the chi squared test or Fisher's exact test where appropriate. Affecting factors for virus infection among COPD exacerbations were compared with the use of univariate and multivariate logistic regression analysis. $P$ values less than 0.05 were considered statistically significant. 


\section{Results}

Study subjects

During the study period, we enrolled 278 episodes of exacerbation in 213 patients with COPD. The demographic and clinical characteristics of the enrolled subjects were described in Table 1 . The majority of patients were males $(\mathrm{n}=140,65.7 \%)$ and the mean age was $69.2 \pm 11.0$ years. The mean $\mathrm{FEV}_{1}$ (\% of predicted) was $44.7 \pm 20.9 \%$, and $63.4 \%$ of patients were in stage 3 or 4 based on GOLD classifications.

\section{Prevalence of virus infection and detected viruses in $C O P D$ exacerbations}

Among the enrolled 213 patients with COPD exacerbations, 62 subjects $(29.1 \%)$ showed positive viral detection. Of all 278 episodes of COPD exacerbations, respira- tory viruses were detected in 78 episodes $(28.1 \%)$. In 9 episodes $(11.5 \%)$, more than one viral pathogens were detected. Rhinovirus was the most commonly identified virus ( $\mathrm{n}=33,38.8 \%$ of all detected viruses), followed by $\operatorname{RSV}(\mathrm{n}=12,14.1 \%)$, coronavirus $(\mathrm{n}=10,11.8 \%)$, influenza $A(n=9,10.6 \%)$, parainfluenza $(n=7,8.2 \%)$, adenovirus $(\mathrm{n}=7,8.2 \%)$ and metapneumovirus $(\mathrm{n}=7,8.2 \%)$ (Fig. 1). In terms of the subtypes of rhinovirus $(\mathrm{n}=34)$, rhinovirus $\mathrm{A} / \mathrm{B}(\mathrm{n}=32)$ was most common with two episodes of rhinovirus type C. Of seven episodes of parainfluenza, there were six episodes of type 1 and one episode of type 3 parainfluenza infection. Regarding coronavirus subtypes $(n=10)$, six episodes were coronavirus 229E/NL63 and the other four episodes were coronavirus OC43. There were no subjects with influenza B infection in the study period. Fig. 2 illustrates the variance of the occurrence of total exacerbations of COPD and respiratory virus infec-

Table 1. Demographic and clinical characteristics of the subjects.

\begin{tabular}{|c|c|c|c|c|}
\hline & $\begin{array}{c}\text { Total } \\
(\mathrm{n}=\mathbf{2 1 3})\end{array}$ & $\begin{array}{c}\text { Males } \\
(n=140)\end{array}$ & $\begin{array}{c}\text { Females } \\
(n=73)\end{array}$ & $P$ value \\
\hline Age (years) & $69.2 \pm 11.0$ & $70.8 \pm 10.5$ & $66.1 \pm 11.2$ & 0.002 \\
\hline BMI $\left(\mathrm{kg} / \mathrm{m}^{2}\right)$ & $21.8 \pm 4.0$ & $21.3 \pm 3.7$ & $22.6 \pm 4.3$ & 0.027 \\
\hline Current smoker (n, \%) & $57(26.3 \%)$ & $54(38.6 \%)$ & $3(4.1 \%)$ & $<0.001$ \\
\hline \multicolumn{5}{|l|}{ Spirometry (post- } \\
\hline \multicolumn{5}{|l|}{ bronchodilator) } \\
\hline FVC (\% predicted $)$ & $62.0 \pm 19.1$ & $61.0 \pm 16.6$ & $63.8 \pm 23.1$ & NS \\
\hline $\mathrm{FEV}_{1}(\%$ predicted $)$ & $44.7 \pm 20.9$ & $40.9 \pm 18.1$ & $52.0 \pm 23.9$ & 0.001 \\
\hline $\mathrm{FEV}_{1} / \mathrm{FVC}(\%)$ & $53.9 \pm 15.2$ & $50.6 \pm 15.1$ & $60.3 \pm 13.3$ & $<0.001$ \\
\hline GOLD stage (n, \%) & & & & 0.002 \\
\hline 1 & $10(4.7 \%)$ & $2(1.4 \%)$ & $8(11.0 \%)$ & \\
\hline 2 & $68(31.9 \%)$ & $41(29.3 \%)$ & $27(37.0 \%)$ & \\
\hline 3 & $75(35.2 \%)$ & $50(35.7 \%)$ & $25(34.2 \%)$ & \\
\hline 4 & $60(28.2 \%)$ & $47(33.6 \%)$ & $13(17.8 \%)$ & \\
\hline \multicolumn{5}{|l|}{$\begin{array}{l}\text { History of hospitalization } \\
\text { due to COPD exacerbation } \\
(\mathrm{n}, \%)\end{array}$} \\
\hline ever & $138(64.8 \%)$ & $90(64.3 \%)$ & $48(65.8 \%)$ & NS \\
\hline in the last 12 months & $76(35.7 \%)$ & $48(34.3 \%)$ & $28(38.4 \%)$ & NS \\
\hline \multicolumn{5}{|l|}{ Medication before } \\
\hline ICS/LABA combination & $71(33.3 \%)$ & $47(33.6 \%)$ & $24(32.9 \%)$ & NS \\
\hline LAMA & $81(38.0 \%)$ & $61(43.6 \%)$ & $20(27.4 \%)$ & 0.015 \\
\hline theophylline & $109(51.2 \%)$ & $75(53.6 \%)$ & $34(46.6 \%)$ & NS \\
\hline Positive virus detection & $62(29.1 \%)$ & $29(20.7 \%)$ & $33(45.2 \%)$ & $<0.001$ \\
\hline
\end{tabular}

Continuous values are presented as mean $\pm \mathrm{SD}$ and categorical variables as numbers (\%).

$\mathrm{BMI}$, body mass index; $\mathrm{FVC}$, forced vital capacity; $\mathrm{FEV}_{1}$, forced expiratory volume in $1 \mathrm{sec}$; ICS, inhaled corticosteroids; LABA, long-acting $\beta_{2}$ agonists; LAMA, long acting muscarinic antagonists; NS, not significant. 
tions depending on months. While the total number of COPD exacerbations were higher in winter, exacerbations by virus infection lasted from winter to early summer. These findings suggest that the contribution of viral infection to exacerbations of COPD varies over seasons and viral infections are more frequent triggers leading to exacerbations of COPD from January to June (up to $45 \%$ ) than the other seasons.

As to the repeated virus-induced exacerbations, seven (4 males and 3 females) of 62 subjects experience more than one episodes, while the other 55 subjects had just one episode of viral infection-related exacerbations. In six of seven subjects with multiple viral infection episodes, the detected viruses were different between the first and the next episodes. The causative viruses related with multiple

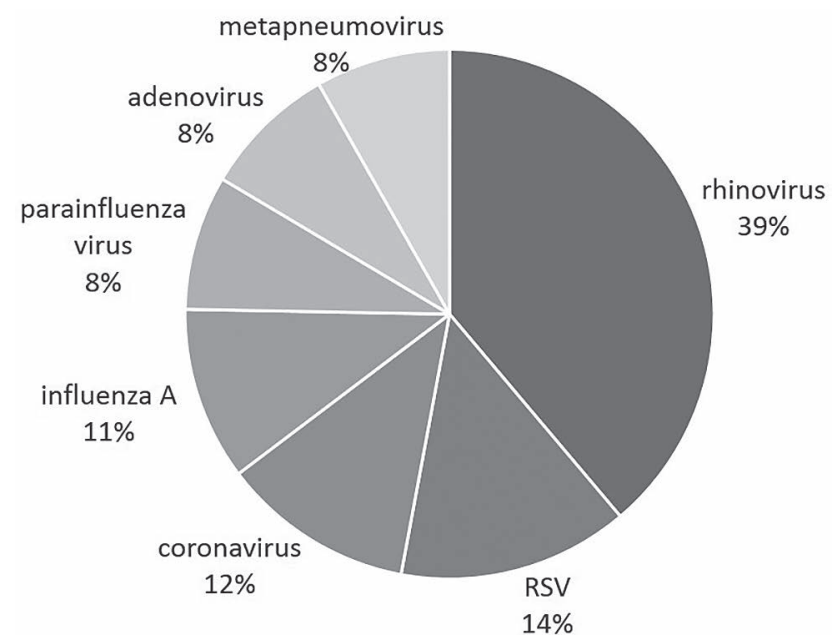

Fig. 1. Viruses detected in nasopharyngeal swab from the hospitalized patients with COPD exacerbation.

The percentages show the proportions of each respiratory virus among the total viral detection. episodes of viral detections were rhinovirus $(38.9 \%)$, coronavirus $(16.7 \%)$, RSV $(11.1 \%)$, parainfluenza $(11.1 \%)$, adenovirus (11.1\%), influenza A (5.6\%) and metapneumovirus $(5.6 \%)$ in descending order.

Factors associated with susceptibility to viral infections in COPD exacerbations

Next, we examined if there is a difference of demographic and clinical characteristics between COPD exacerbations induced viral infections and non-viral infections. The rate of females was significantly higher in patients with positive viral detection (46.2\%) than those with negative detection $(27.5 \%)(P=0.004)$, while there was no difference in mean age between the groups (Table 2). The patients with viral infection had higher BMI than non-viral infection group. There was no significant difference of mean age and the prevalence of current smoking between the groups. Then, we tried to explore if the severity of COPD is associated with viral infection in the patients with exacerbations of COPD. In terms of lung function after bronchodilator inhalation, the patients with viral infection showed higher $\mathrm{FEV}_{1}(\%$ predicted value $)(47.0 \pm 22.9$ vs. $41.1 \pm 18.5, P=0.008)$ and FVC (\% predicted value) (63.9 \pm 20.1 vs. $58.7 \pm 17.8, P=0.038)$, compared to the nonviral infection group. The COPD stages, based on GOLD classifications, were different between viral infection and non-viral infection groups, with higher classes in viral infection group $(P=0.004)$. Since the experience of COPD exacerbation in the past determines the future risk of exacerbation (Donaldson et al. 2002), we compared the previous history of exacerbations of COPD between the groups. However, there was no significant difference in the number of COPD exacerbations in the lifetime and in the past 12 months before enrollment between the patients with and without viral infection. In addition, we compared the medi-

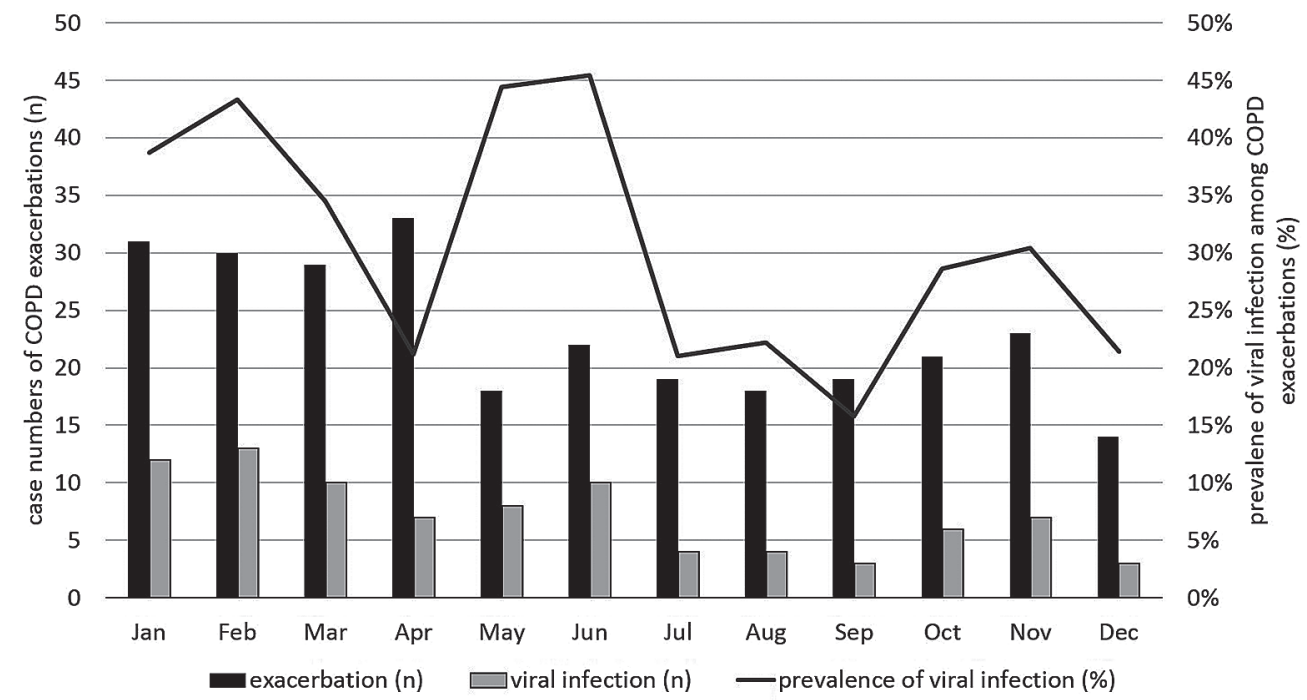

Fig. 2. Variation of virus detection in COPD exacerbations.

Bar graphs show the total numbers of COPD exacerbations (black) and respiratory virus detection (gray) each month during two years. Line graph illustrates the prevalence of respiratory virus infection among COPD exacerbations. 
Table 2. Factors associated with susceptibility to viral infections in COPD exacerbations.

\begin{tabular}{|c|c|c|c|c|}
\hline & \multirow{2}{*}{$\begin{array}{c}\text { Positive viral } \\
\text { detection } \\
(n=78)\end{array}$} & \multirow{2}{*}{$\begin{array}{l}\text { Negative viral } \\
\text { detection } \\
(\mathrm{n}=\mathbf{2 0 0})\end{array}$} & \multicolumn{2}{|c|}{$P$ value } \\
\hline & & & $\begin{array}{c}\text { univariate } \\
\text { analysis }\end{array}$ & $\begin{array}{c}\text { multivariate } \\
\text { analysis }\end{array}$ \\
\hline Female (n, \%) & $36(46.2 \%)$ & $55(27.5 \%)$ & 0.004 & 0.010 \\
\hline Age (years) & $71.2 \pm 10.4$ & $69.1 \pm 11.2$ & NS & NS \\
\hline $\operatorname{BMI}\left(\mathrm{kg} / \mathrm{m}^{2}\right)$ & $22.7 \pm 4.2$ & $21.5 \pm 3.9$ & 0.027 & NS \\
\hline Current smoker (n, \%) & $15(19.2 \%)$ & $55(27.5 \%)$ & NS & NS \\
\hline \multicolumn{5}{|l|}{ Spirometry (post- } \\
\hline \multicolumn{5}{|l|}{ bronchodilator) } \\
\hline FVC (\% predicted $)$ & $63.9 \pm 20.1$ & $58.7 \pm 17.8$ & 0.038 & NS \\
\hline $\mathrm{FEV}_{1}(\%$ predicted $)$ & $47.0 \pm 22.9$ & $41.1 \pm 18.5$ & 0.008 & NS \\
\hline $\mathrm{FEV}_{1} / \mathrm{FVC}(\%)$ & $56.3 \pm 14.3$ & $53.0 \pm 16.4$ & NS & NS \\
\hline GOLD stage $(n, \%)$ & & & 0.004 & NS \\
\hline 1 & $7(9.0 \%)$ & $12(6.0 \%)$ & & \\
\hline 2 & $22(28.2 \%)$ & $60(30.0 \%)$ & & \\
\hline 3 & $30(38.5 \%)$ & $63(31.5 \%)$ & & \\
\hline 4 & $19(24.4 \%)$ & $65(32.5 \%)$ & & \\
\hline \multirow{3}{*}{\multicolumn{5}{|c|}{$\begin{array}{l}\text { History of hospitalization } \\
\text { due to COPD exacerbation } \\
\text { (n, \%) }\end{array}$}} \\
\hline & & & & \\
\hline & & & & \\
\hline ever & $50(64.9 \%)$ & $146(73.4 \%)$ & NS & NS \\
\hline in the last 12 months & $36(46.8 \%)$ & $93(46.7 \%)$ & NS & NS \\
\hline \multicolumn{5}{|l|}{ Medication before } \\
\hline \multicolumn{5}{|l|}{ exacerbation $(n, \%)$} \\
\hline ICS/LABA combination & $30(39.0 \%)$ & $74(37.2 \%)$ & NS & NS \\
\hline LAMA & $36(46.8 \%)$ & $89(44.5 \%)$ & NS & NS \\
\hline theophylline & $40(51.9 \%)$ & $110(55.3 \%)$ & NS & NS \\
\hline
\end{tabular}

Continuous values are presented as mean $\pm \mathrm{SD}$ and categorical variables as numbers $(\%)$. $\mathrm{BMI}$, body mass index; FVC, forced vital capacity; $\mathrm{FEV}_{1}$, forced expiratory volume in 1 sec; ICS, inhaled corticosteroids; LABA, long-acting $\beta_{2}$ agonists; LAMA, long acting muscarinic antagonists; NS, not significant.

cations before exacerbation to examine if the use of inhaled corticosteroids (ICS) or long-acting bronchodilators [longacting $\beta 2$ agonists (LABA) or long-acting muscarinic antagonists (LAMA)] affected the viral infection in COPD exacerbations (Table 2). There were no notable differences between the groups, irrespective of the use of ICS/LABA, LAMA or theophylline. In multivariate regression analysis adjusting for sex, age, BMI, lung function and history of exacerbations, female subjects were found to be significantly associated with COPD exacerbations induced by viral infections (Odds ratio 2.58, 95\% Confidence Interval $1.25-5.31, P=0.010$ ), while the other factors did not show significant relationships.

\section{Vaccination and viral infection in COPD exacerbations}

Since the influenza virus was known as an important pathogen inducing exacerbations of COPD, we compared if influenza vaccination affects the viral infections in the study subjects. The vaccination rate of influenza virus was similar between viral infection and non-viral infection group $(60.3 \%$ vs. $57.5 \%)$ (Table 3$)$. However, among the viral infection group, the patients with influenza infection showed a lower rate of influenza vaccination $(28.6 \%)$ than those with the other viral infection (67.2\%). Pneumococcal vaccinations were found to be similar in viral infection and non-viral infection group $(57.7 \%$ vs. $50.5 \%)$, showing no significant effect on the future viral infection in COPD exacerbations.

Severity of COPD exacerbations according to viral infections

Lastly, we assessed whether there are differences in the severity of COPD exacerbations between viral infections and non-viral infections. First, there were no significant 
Table 3. Previous vaccination in patients with positive and negative viral detection in COPD exacerbations.

\begin{tabular}{lccc}
\hline & $\begin{array}{c}\text { Positive viral } \\
\text { detection }\end{array}$ & $\begin{array}{c}\text { Negative viral } \\
\text { detection }\end{array}$ & P value \\
& $(\mathbf{n = 7 8 )}$ & $\mathbf{( n = 2 0 0 )}$ & \\
\hline Influenza vaccine in the last 12 months & $47(60.3 \%)$ & $115(57.5 \%)$ & NS \\
pneumococcal vaccine ever & $45(57.7 \%)$ & $101(50.5 \%)$ & NS \\
\hline
\end{tabular}

Values are presented as numbers (\%).

NS, not significant.

Table 4. Comparisons of the severity of COPD exacerbations between positive and negative viral detection.

\begin{tabular}{|c|c|c|c|}
\hline & $\begin{array}{c}\text { Positive viral } \\
\text { detection } \\
(\mathrm{n}=78)\end{array}$ & $\begin{array}{l}\text { Negative viral } \\
\text { detection } \\
(\mathrm{n}=\mathbf{2 0 0})\end{array}$ & $P$ value \\
\hline \multicolumn{4}{|l|}{ Symptoms at hospitalization } \\
\hline Fever & $21(26.9)$ & $59(29.5)$ & NS \\
\hline Sore throat & $4(5.1)$ & $8(4.0)$ & NS \\
\hline Increased dyspnea & $74(94.9)$ & $191(95.5)$ & NS \\
\hline Increased sputum & $72(92.3)$ & $174(87.0)$ & NS \\
\hline Purulent sputum & $57(73.1)$ & $147(73.5)$ & NS \\
\hline \multicolumn{4}{|l|}{ Laboratory tests } \\
\hline Leukocytosis $\left(\mathrm{WBC}>10,000 / \mathrm{mm}^{3}\right)$ & $25(32.1 \%)$ & $63(31.5 \%)$ & NS \\
\hline Elevated CRP (> 10X ULN) & $26(33.3 \%)$ & $74(37.0 \%)$ & NS \\
\hline \multicolumn{4}{|l|}{ Hospital course } \\
\hline Hospital days & $15.7 \pm 14.1$ & $16.0 \pm 12.7$ & NS \\
\hline ICU care & $7(9.2 \%)$ & $22(11.0 \%)$ & NS \\
\hline In hospital death & $6(7.7 \%)$ & $11(5.5 \%)$ & NS \\
\hline
\end{tabular}

Continuous values are presented as mean $\pm \mathrm{SD}$, and categorical variables as numbers $(\%)$.

ICU, intensive care unit; CRP, C-reactive protein; ULN, upper limit of normal; NS, not significant; WBC, white blood cells.

differences in the frequency of systemic or respiratory symptoms (fever, sore throat, increased dyspnea, increased and purulent sputum) at the time of admission between the patients with and without viral infection in COPD exacerbations (Table 4). In addition, the laboratory tests performed within 24 hours of admission showed no significant difference between the groups. Elevation in white blood cell counts and C-reactive protein (CRP) levels in serum was similar in both groups. Lastly, regarding clinical outcomes of COPD exacerbations, the total hospital days was about the same between viral infection $(15.7 \pm 14.1$ days $)$ and non-viral infection group $(16.0 \pm 12.7$ days $)$ and the percentage of intensive care unit (ICU) use was not different between the groups $(9.2 \%$ vs. $11.0 \%)$. Furthermore, the mortality rate in viral infection group was not significantly different from that in non-viral infection group $(7.7 \%$ vs. 5.5\%). These findings suggest that viral infection in COPD exacerbation is not different from those with non-viral causes.

\section{Discussion}

In this two-year observational study, we examined the prevalence of viral infections and identified each viral pathogen using multiplex PCR in the hospitalized patients with exacerbations of COPD. We also analyzed the factors associated with susceptibility to viral infections in COPD exacerbations and investigated the relationships between viral infections and the severity of COPD exacerbations. The overall prevalence of viral infection among the patients with COPD was found to be $28.1 \%$. The most common 
viral pathogen was rhinovirus (38.8\%) in our study population and the others were identified as RSV, coronavirus, influenza, parainfluenza, adenovirus and metapneumovirus in descending order. We found for the first time that female gender was more closely associated with viral infection. Vaccination of influenza and pneumococcus did not show a significant relationship with viral infections in COPD exacerbations. Contrary to the previous reports, there was no difference in symptoms, laboratory tests for acute inflammations and hospital courses such as hospital days, ICU use or mortality, between COPD exacerbations induced by respiratory virus infections and non-virus infections.

The detection rate of respiratory viruses is largely affected by the detection methods. For the detection of viral infection in COPD, various techniques have been used including culture, serology, microarray and PCR-based technique (Zwaans et al. 2014). While earlier studies on the roles of respiratory virus in COPD exacerbations used serology and virus culture, the detection rate were largely low. A previous study using cell culture and/or serology revealed viruses in only $15-20 \%$ of exacerbation cases (Beasley et al. 2012). Introduction of PCR or reverse transcriptase (RT)-PCR improved the detection rate of virus infection in the respiratory system. A few studies compared the detection rates of different techniques in detecting virus in COPD exacerbations and demonstrated that PCR or RT-PCR is superior to serology or culture in terms of detection rate (Seemungal et al. 2001; Beckham et al. 2005; De Serres et al. 2009). Now PCR-based technique is the most frequently used for the detection of respiratory virus and the detection rates of respiratory viruses ranged from $22 \%$ to $56 \%$ among COPD exacerbations (Rohde et al. 2003; Ko et al. 2007a). In a meta-analysis by $\mathrm{Wu}$ et al. (2014), 17 studies were eligible for analysis and weighted overall prevalence of respiratory viruses in exacerbations of COPD was 39.3\%. Multiplex PCR improved the detection rate of respiratory viruses in many respiratory diseases (Roh et al. 2008). However, PCR is not the gold standard for virus detection and it is possible that there will be false negative cases of virus infection in the use of multiplex PCR in our analysis. In addition to detection methods, the variation of the prevalence rate of respiratory viruses is influenced by the heterogeneity of sample types and methods of collecting samples. Various upper (nose, nasopharynx and throat) and lower respiratory tract (sputum) samples have been used for the detection of respiratory viruses. For collecting upper airway samples, wash, swabs, lavage and aspiration have been used, while spontaneous or induced sputum was most frequently used for lower respiratory samples (Zwaans et al. 2014). Detection rate of respiratory virus varies depending on samples and collecting methods. Thus, false negative results would be possibly related with the types and collecting methods of the specimen.

Moreover, in a systematic review by Mohan et al. (2010) on the viral infection in COPD exacerbation, geographic variations of viral prevalence was found with the highest prevalence in Europe (43.2\%) and the lowest in Asia (22.1\%). Also, it has been also suggested that contribution of each virus may vary depending on geography. While rhinovirus was the most common virus identified from studies in most western countries, including UK (Seemungal et al. 2001; McManus et al. 2008), Germany (Rohde et al. 2003), US (Beckham et al. 2005) and Australia (Hutchinson et al. 2007), influenza was the most commonly detected in the Hong Kong study (Ko et al. 2007a). This study in Korea revealed that the overall prevalence of viral infections in the hospitalized patients with COPD exacerbations was $28.1 \%$, which is comparable to the findings from Hong Kong (Ko et al. 2007a). However, contrary to the results in Hong Kong, where influenza dominated, rhinovirus infection was by far more prevalent than the others including influenza in this study. Since influenza infection is frequently affected by the epidemic factors, we need more data from many countries to determine the reality of viral infection in COPD exacerbation in Asia (Tan et al. 2003; Ko et al. 2007a, b). Whether influenza vaccination reduces influenza infection in COPD has been questioned and tested in the previous studies. So far it seems that there is no close relationship between influenza vaccination and its infection in COPD exacerbations (Zwaans et al. 2014). In a previous study (Ko et al. 2007a), positive rate for influenza was similar between those who got influenza vaccination and those not. Similarly, in our data, there was no difference in the proportions of subjects who received influenza vaccination between patients with positive and negative detection of respiratory viruses. Moreover, streptococcal vaccination also was not associated with viral infection among the patients with exacerbations of COPD. For more direct answers to the protective role of influenza vaccination on the prevention of COPD exacerbations, prospective clinical studies are needed.

What is intriguing in our findings is the seasonal variations of viral infection in COPD exacerbations. Previous studies have shown inconsistent patterns of viral infection in COPD exacerbations. In an Australian study of the patients with COPD exacerbations requiring ventilation, most exacerbation episodes occurred in winter and spring season suggesting high seasonal variation (Cameron et al. 2006). Contrary to this, the positive rate of virus identification was highest in summer (July to September) in the results from Hong Kong (Ko et al. 2007a). In our study, whereas the incidence of the exacerbations of COPD peaked in winter, the viral infection and its prevalence among COPD exacerbation lasted until summer. These findings support the idea of the geographic variation of viral infection in exacerbations of COPD. In addition, it can be speculated that variations of epidemics of each virus, such as influenza and rhinovirus, over seasons and years might affect the results (Monto 2002). Therefore, in the interpretation of findings of the relationship between viral infection and COPD exacerbations, we need to consider the seasonal variation of virus infections. 
It is well known that COPD is at increased risk of respiratory virus infection due to impaired airway epithelial cells and decreased mucociliary function (Sajjan 2013). However, the host factors or characteristics of COPD associated with increased risk of viral infections are not well determined yet. A previous study showed that frequent exacerbations of COPD are related to increased susceptibility of common cold (Hurst et al. 2005). Low lung function also has been suggested to be associated with positive respiratory virus detection in the exacerbation of COPD (McManus et al. 2008), while there was no difference in $\mathrm{FEV}_{1}$ in other studies (Ko et al. 2007a; Dimopoulos et al. 2012). We compared the demographic and clinical characteristics of COPD patients with and without virus detection to find the factors linked to respiratory virus infection in COPD exacerbations. Contrary to our expectation, we found that female sex, not lung function or exacerbation history, was significantly associated with respiratory virus infection in the patients with COPD exacerbations in a multivariate regression analysis. We do not have any explanation for the relationship between sex and susceptibility for respiratory virus infection at present. Further studies are needed to confirm the link and to reveal the mechanisms.

So far several studies have shown that COPD exacerbations triggered by viral infection are more severe in symptoms and more protracted in recovery time than nonviral causes. Severe symptoms of colds, such as runny nose and sore throat, and fever were more frequently observed in the patients with COPD exacerbations and positive respiratory virus (Seemungal et al. 2001; Tan et al. 2003; Hutchinson et al. 2007; Camargo et al. 2008). In addition, delay in recovery and longer hospital stay was observed in the patients with virus detection (Seemungal et al. 2001; Dimopoulos et al. 2012). However, in our study subjects with exacerbation of COPD, there was no significant difference of hospital days, ICU use or mortality. Because we included only hospitalized patients for COPD exacerbations, it is possible that patients with virus infections were admitted earlier than non-viral infection. Additionally, these inconsistent findings of clinical outcomes of virus positive COPD exacerbations might be possibly explained by the heterogeneity of study population and composition of virus pathogens. As a biomarker for identification of virus infection in the patients with COPD exacerbation, serum inflammatory markers have been investigated. Nonetheless, total leukocyte count, CRP and procalcitonin failed to show significant association with viral infection in COPD exacerbations (Chang et al. 2015). Similarly, CRP and total leukocyte count, were also similar between groups in our analysis. Further studies should be followed to identify biomarkers related with the viral infection in the exacerbations of COPD.

The results of our study should be interpreted with caution because there are a few limitations of this study. First, we included only hospitalized patients, not all the patients with COPD exacerbations. Thus the results of viral infection are limited to the severe cases of exacerbations. However, selecting only the hospitalized patients would be beneficial in improving the diagnostic certainty and homogeneity of the clinical characteristics. Thus most of the previous studies on viral examination in COPD exacerbations included the hospitalized patients (Mohan et al. 2010). Second, since we did not include the other microbiological studies in the methods, the other causes of microbiological infection, such as bacteria, were not presented in this study. The results of detection methods other than PCR and bacteriological studies would be useful to understand the other causes of exacerbations of COPD. Lastly, the PCR method is limited in discriminating new infection before exacerbation from the presence of virus even at stable state. Therefore, it is likely that some cases of positive detection might be false positive case.

In conclusion, using a multiplex PCR we evaluated the viral infection among the patients with COPD exacerbations and assessed the susceptibility and the severity of viral infection-induced COPD exacerbations in a single center in Korea for two years. The overall prevalence of viral infection was relatively low compared with the previous reports and the dominant viral pathogen was rhinovirus. The prevalence rate of viral infection was high in winter and early summer suggesting seasonal variations. Female subjects were associated with the higher risk of respiratory virus infection in COPD exacerbations. The severity of COPD exacerbations was not different between viral infection and non-viral infection causes. Considering the importance of viral infection in COPD exacerbations, much attention, and vigorous strategies are needed to improve management of COPD.

\section{Acknowledgments}

This work was supported by the research fund of Hanyang University (HY-2011-MC).

\section{Conflict of Interest}

The authors declare no conflict of interest.

\section{References}

Beasley, V., Joshi, P.V., Singanayagam, A., Molyneaux, P.L., Johnston, S.L. \& Mallia, P. (2012) Lung microbiology and exacerbations in COPD. Int. J. Chron. Ostruct. Pulmon. Dis., 7, 555-569.

Beckham, J.D., Cadena, A., Lin, J., Piedra, P.A., Glezen, W.P., Greenberg, S.B. \& Atmar, R.L. (2005) Respiratory viral infections in patients with chronic, obstructive pulmonary disease. J. Infect., 50, 322-330.

Boixeda, R., Rabella, N., Sauca, G., Delgado, M., Martinez-Costa, X., Mauri, M., Vicente, V., Palomera, E., Serra-Prat, M. \& Capdevila, J.A. (2012) Microbiological study of patients hospitalized for acute exacerbation of chronic obstructive pulmonary disease (AE-COPD) and the usefulness of analytical and clinical parameters in its identification (VIRAE study). Int. J. Chron. Ostruct. Pulmon. Dis., 7, 327-335.

Camargo, C.A. Jr., Ginde, A.A., Clark, S., Cartwright, C.P., Falsey, A.R. \& Niewoehner, D.E. (2008) Viral pathogens in acute exacerbations of chronic obstructive pulmonary disease. 
Intern. Emerg. Med., 3, 355-359.

Cameron, R.J., de Wit, D., Welsh, T.N., Ferguson, J., Grissell, T.V. \& Rye, P.J. (2006) Virus infection in exacerbations of chronic obstructive pulmonary disease requiring ventilation. Intensive Care Med., 32, 1022-1029.

Chang, C.H., Tsao, K.C., Hu, H.C., Huang, C.C., Kao, K.C., Chen, N.H., Yang, C.T., Tsai, Y.H. \& Hsieh, M.J. (2015) Procalcitonin and C-reactive protein cannot differentiate bacterial or viral infection in COPD exacerbation requiring emergency department visits. Int. J. Chron. Ostruct. Pulmon. Dis., 10, 767-774.

De Serres, G., Lampron, N., La Forge, J., Rouleau, I., Bourbeau, J., Weiss, K., Barret, B. \& Boivin, G. (2009) Importance of viral and bacterial infections in chronic obstructive pulmonary disease exacerbations. J. Clin. Virol., 46, 129-133.

Dimopoulos, G., Lerikou, M., Tsiodras, S., Chranioti, A., Perros, E., Anagnostopoulou, U., Armaganidis, A. \& Karakitsos, P. (2012) Viral epidemiology of acute exacerbations of chronic obstructive pulmonary disease. Pulm. Pharmacol. Ther., 25, 12-18.

Donaldson, G.C., Seemungal, T.A., Bhowmik, A. \& Wedzicha, J.A. (2002) Relationship between exacerbation frequency and lung function decline in chronic obstructive pulmonary disease. Thorax, 57, 847-852.

Foster, T.S., Miller, J.D., Marton, J.P., Caloyeras, J.P., Russell, M.W. \& Menzin, J. (2006) Assessment of the economic burden of COPD in the U.S.: a review and synthesis of the literature. $C O P D, \mathbf{3}, 211-218$.

Hurst, J.R., Donaldson, G.C., Wilkinson, T.M., Perera, W.R. \& Wedzicha, J.A. (2005) Epidemiological relationships between the common cold and exacerbation frequency in COPD. Eur. Respir. J., 26, 846-852.

Hutchinson, A.F., Ghimire, A.K., Thompson, M.A., Black, J.F., Brand, C.A., Lowe, A.J., Smallwood, D.M., Vlahos, R., Bozinovski, S., Brown, G.V., Anderson, G.P. \& Irving, L.B. (2007) A community-based, time-matched, case-control study of respiratory viruses and exacerbations of COPD. Respir. Med., 101, 2472-2481.

Kim, S.R., Ki, C.S. \& Lee, N.Y. (2009) Rapid detection and identification of 12 respiratory viruses using a dual priming oligonucleotide system-based multiplex PCR assay. J. Virol. Methods, 156, 111-116.

Ko, F.W., Ip, M., Chan, P.K., Chan, M.C., To, K.W., Ng, S.S., Chau, S.S., Tang, J.W. \& Hui, D.S. (2007a) Viral etiology of acute exacerbations of COPD in Hong Kong. Chest, 132, 900-908.

Ko, F.W., Ip, M., Chan, P.K., Fok, J.P., Chan, M.C., Ngai, J.C., Chan, D.P. \& Hui, D.S. (2007b) A 1-year prospective study of the infectious etiology in patients hospitalized with acute exacerbations of COPD. Chest, 131, 44-52.

Matsumoto, K. \& Inoue, H. (2014) Viral infections in asthma and COPD. Respir. Investig., 52, 92-100.

McManus, T.E., Marley, A.M., Baxter, N., Christie, S.N., O’Neill, H.J., Elborn, J.S., Coyle, P.V. \& Kidney, J.C. (2008) Respira- tory viral infection in exacerbations of COPD. Respir. Med., 102, 1575-1580.

Mohan, A., Chandra, S., Agarwal, D., Guleria, R., Broor, S., Gaur, B. \& Pandey, R.M. (2010) Prevalence of viral infection detected by PCR and RT-PCR in patients with acute exacerbation of COPD: a systematic review. Respirology, 15, 536-542.

Monto, A.S. (2002) The seasonality of rhinovirus infections and its implications for clinical recognition. Clin. Ther., 24, 19871997.

Roh, K.H., Kim, J., Nam, M.H., Yoon, S., Lee, C.K., Lee, K., Yoo, Y., Kim, M.J. \& Cho, Y. (2008) Comparison of the Seeplex reverse transcription PCR assay with the R-mix viral culture and immunofluorescence techniques for detection of eight respiratory viruses. Ann. Clin. Lab. Sci., 38, 41-46.

Rohde, G., Wiethege, A., Borg, I., Kauth, M., Bauer, T.T., Gillissen, A., Bufe, A. \& Schultze-Werninghaus, G. (2003) Respiratory viruses in exacerbations of chronic obstructive pulmonary disease requiring hospitalisation: a case-control study. Thorax, 58, 37-42.

Sajjan, U.S. (2013) Susceptibility to viral infections in chronic obstructive pulmonary disease: role of epithelial cells. Curr. Opin. Pulm. Med., 19, 125-132.

Seemungal, T., Harper-Owen, R., Bhowmik, A., Moric, I., Sanderson, G., Message, S., Maccallum, P., Meade, T.W., Jeffries, D.J., Johnston, S.L. \& Wedzicha, J.A. (2001) Respiratory viruses, symptoms, and inflammatory markers in acute exacerbations and stable chronic obstructive pulmonary disease. Am. J. Respir. Crit. Care Med., 164, 1618-1623.

Sung, H., Park, S.J., Woo, Y.D., Choi, B.H. \& Kim, M.N. (2008) Evaluation of Seeplex RV detection kit for detecting rhinovirus, human metapneumovirus, and coronavirus. Korean $J$. Lab. Med., 28, 109-117.

Tan, W.C., Xiang, X., Qiu, D., Ng, T.P., Lam, S.F. \& Hegele, R.G. (2003) Epidemiology of respiratory viruses in patients hospitalized with near-fatal asthma, acute exacerbations of asthma, or chronic obstructive pulmonary disease. Am. J. Med., 115, 272-277.

Vestbo, J., Hurd, S.S., Agusti, A.G., Jones, P.W., Vogelmeier, C., Anzueto, A., Barnes, P.J., Fabbri, L.M., Martinez, F.J., Nishimura, M., Stockley, R.A., Sin, D.D. \& Rodriguez-Roisin, R. (2013) Global strategy for the diagnosis, management, and prevention of chronic obstructive pulmonary disease: GOLD executive summary. Am. J. Respir. Crit. Care Med., 187, 347-365.

Wedzicha, J.A. \& Seemungal, T.A. (2007) COPD exacerbations: defining their cause and prevention. Lancet, 370, 786-796.

Wu, X., Chen, D., Gu, X., Su, X., Song, Y. \& Shi, Y. (2014) Prevalence and risk of viral infection in patients with acute exacerbation of chronic obstructive pulmonary disease: a meta-analysis. Mol. Biol. Rep., 41, 4743-4751.

Zwaans, W.A., Mallia, P., van Winden, M.E. \& Rohde, G.G. (2014) The relevance of respiratory viral infections in the exacerbations of chronic obstructive pulmonary disease. A systematic review. J. Clin. Virol., 61, 181-188. 